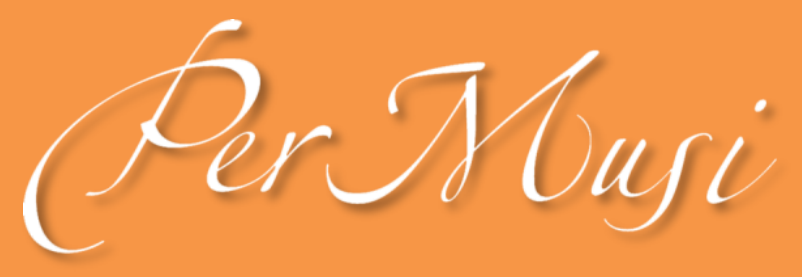

eISSN 2317-6377

\title{
Multiplicidade de recursos vocais, dramáticos e expressivos a partir da análise da obra Sound - para quatro vozes femininas, luz, cena e amplificação - de Luiz Carlos Csekö
}

\author{
Diogo Rebel e Carvalho \\ https://orcid.org/0000-0003-2894-9253 \\ Instituto Federal Fluminense, Coordenação de Licenciatura em Música \\ diogo.carvalho@iff.edu.br
}

SCIENTIFIC ARTICLE

Submitted date: 24 jun 2021

Final approval date: 07 sep 2021

Resumo: O presente artigo tem como objetivo investigar a multiplicidade de recursos vocais, dramáticos e expressivos, além da diversidade de estilos e tendências nas interfaces entre canto e performance, e a ampliação do espaço cênicomusical a partir da análise da obra Sound, para quatro vozes femininas, luz, cena e amplificação, do compositor Luiz Carlos Csekö. Após um breve relato da trajetória do compositor, serão apresentadas as estratégias utilizadas por Csekö para registrar sua obra, como a Notação Gráfica Híbrida, o Tempo em Suspensão e as Interfaces com Multimeios e Intermeios, além da utilização de microfonação e amplificação em sua abordagem do conceito de amálgama eletroacústico. Além de Sound, serão citadas três obras vocais selecionadas, onde são, também, exploradas pelo compositor, a enorme gama de possibilidades e de materiais sonoros particulares, a manipulação do texto traduzido em texturas e as indicações de elementos cênicos ao intérprete.

Palavras-chave: Música vocal contemporânea; Interfaces canto performance; Notação gráfica híbrida; L. C. Csekö.

TITLE: MULTIPLICITY OF VOCAL DRAMATIC AND EXPRESSIVE RESOURCES FROM THE ANALYSIS OF THE WORK SOUND - FOR FOUR FEMALE VOICES, LIGHT, SCENE AND AMPLIFICATION - BY LUIZ CARLOS CSEKÖ

Abstract: This article aims to investigate the multiplicity of vocal, dramatic and expressive resources, besides to the diversity of styles and trends in the interfaces between singing and performance and the expansion of the scenicmusical space based on the analysis of the work Sound, for four female voices, light, scene and amplification by composer Luiz Carlos Csekö. After a brief account of the composer's trajectory, the strategies used by Csekö to register his work such as Hybrid Graphic Notation, Suspended Time and Interfaces with Multimedia and Intermediates, beyond the use of miking and amplification in his approach to the concept of electroacoustic amalgam. Apart from Sound, three selected vocal works also explored by the composer will be mentioned like the huge range of possibilities and particular sound materials, the manipulation of text translated into textures and indications of scenic elements to the interpreter.

Keywords: Contemporary vocal music; Interfaces singing performance; Hybrid graphic notation; L. C. Csekö. 


\section{Multiplicidade de recursos vocais, dramáticos e expressivos a partir da análise da obra Sound - para quatro vozes femininas, luz, cena e amplificação - de Luiz Carlos Csekö}

Diogo Rebel e Carvalho, Instituto Federal Fluminense, diogo.carvalho@iff.edu.br

\section{Introdução}

Após a estreia do monodrama Pierrot Lunaire, escrito por Arnold Schoenberg em 1911, a música de concerto composta para voz não seria mais a mesma. Afastando-se da consagrada sonoridade vocal da música de concerto tradicional, compositores e intérpretes-cantores passariam a explorar, cada vez mais, uma miríade de novos sons, e as diversas pesquisas realizadas nos campos da fonética e da fisiologia da voz contribuiriam, de forma significativa, para que a música composta a partir da segunda metade do século XX desse à voz um novo enfoque, equiparando o cantor, em termos de virtuosismo e expressividade, a qualquer instrumentista.

Devido à extensa gama de associações, riqueza de suas possibilidades e à capacidade de produzir um amplo espectro de cores e sons, a voz humana foi um dos instrumentos mais receptivos às novas técnicas e processos de composição em diversas obras escritas entre os séculos XX e XXI, em que todo o discurso vocal que, outrora, relacionava-se, quase estritamente, à emissão de sons no espectro cantabile da voz, incorporaria, agora, uma gama de possibilidades e de materiais sonoros particulares: na música vocal contemporânea, portanto, textos podem ser traduzidos em texturas nos quais suas possibilidades fonéticas passam a ser mais importantes do que o seu significado, não mais se tratando de musicalizar a palavra tão somente, mas de extrair dela o conteúdo musical desejado. Expressões vocais como murmúrios, sussurros, gemidos, gritos, estalidos e assobios são alguns dos recursos vocálicos amplamente utilizados em produções atuais.

Tais recursos são manipulados e empregados por Luis Carlos Csekö em sua obra Sound, composta em 1982 para quatro vozes femininas solistas, luz, cena e amplificação.

\section{Luiz Carlos Csekö - O início da trajetória}

Nascido na sexta-feira de carnaval de 1945, poucos meses antes do fim da segunda Grande Guerra, Luiz Carlos Csekö cresceu na cidade de Salvador, Bahia. Como comenta o próprio compositor $^{1}$, seu nascimento

${ }^{1}$ A maior parte das informações pessoais contidas no presente artigo foi reunida a partir das entrevistas realizadas com o compositor entre setembro e outubro de 2014. 
se deu numa conjuntura pitoresca, alegre e eufórica: enquanto, na rua, o povo festejava e comemorava o Carnaval da Bahia, em casa, sua mãe entrava em trabalho de parto, rodeada por familiares, amigos e pela parteira da família, que esperavam ansiosa e esperançosamente pelo nascimento de um menino. Filho de um casal libertário, esquerdista militante e anarco-comunista, Luiz Carlos Csekö foi batizado em homenagem ao líder político e revolucionário brasileiro Luís Carlos Prestes que, ainda como conta o compositor, teria sido seu padrinho se, ironicamente, pudesse entrar numa igreja. Seu pai, húngaro, era violinista e engenheiro eletrônico. Sua mãe, filha de italianos, baiana; feminista e libertária, tocava piano e trabalhava como jornalista e professora.

Csekö iniciou seus estudos de música em Salvador. Com pouco menos de vinte anos de idade, matriculou-se em um curso livre de música, promovido pela Universidade Federal da Bahia, onde começou a estudar trompete. No entanto, durante os quatro anos de dedicação ao instrumento, percebeu que seu rendimento, muito baixo, não o satisfazia como músico. Foi quando decidiu abandonar a carreira de instrumentista. Sua rotina na Escola de Música da UFBA, contudo, aproximou-o de outros jovens que, mais tarde, fundariam o Grupo de Compositores da Bahia. Em entrevista concedida ao compositor Daniel Puig, Csekö recorda:

Voltando de um pesado almoço no restaurante universitário, adentro o então Seminários Livres de Música da UFBA, hoje Escola de Música, e, nessa tarde calorenta e modorrenta, ao passar por uma das salas, escutei sons estranhíssimos. Curioso (sempre fui e continuo, e assim o acaso está do meu lado), bati na porta e mergulhei de cabeça no Gesang der Jünglinge do Stockhausen sendo tocado na vitrola (sistema de som precário da época) em uma aula de história. Fascinado, fiquei e eis que acontece a audição comparada (felizmente não me lembro da aula e sim do som) do Gesang com umas Chansos de Amis de [Guillaume de] Machault e, de quebra, Léonin e Pérotin. Nunca mais fui o mesmo. (Csekö apud Puig 2014)

Em 1968, a fim de ingressar como discente na Universidade Nacional de Brasília, Csekö muda-se para a recém-inaugurada capital do país, e foi ali, durante seus estudos em Composição Musical, que ele desenvolveu as estratégias para registrar suas obras que utiliza até hoje: a Notação Gráfica Híbrida, o Tempo em Suspensão e as Interfaces com Multimeios e Intermeios.

\section{Notação Gráfica Híbrida}

De acordo com Csekö (apud Rebel 2015), seu ideário musical nunca se conformou com a mensura dos tempos em compassos, tal qual o sistema notacional tradicional nos apresenta. Experiências frustradas com compassos alternados e frações de compassos levaram o compositor a concluir que a melhor forma de grafar a música que produzia seria cronometrando, dentro de um espaço gráfico, os eventos sonoros. A esse respeito, em conferência proferida na Juilliard School of Music em 1996, Csekö esclarece:

Como determinar os parâmetros para a duração, incidência de acontecimentos, fluxo e velocidade de um imaginário musical com propulsão própria, imperiosa e rigorosa, ao mesmo tempo que implicita uma grande maleabilidade? Como mensurar sem reter, obstruir ou mutilar este jorro incessante e fugaz? Um híbrido de instrumentos de registro 
se faz claramente necessário, apto a fluxos e refluxos, ao rigor e ao acaso. Decido trabalhar com o tempo cronometrado e tornado também elástico, blocos de circa 5 " onde o espaço gráfico também é proporcional ao som. Esgarço mais ainda o rigor do cronométrico ao utilizar sistematicamente a repetição via simile de eventos graficamente delimitados por retângulos que podem também conter improvisação. A precisão, o rigor do exato é obtido através de um jogo rítmico finamente tecido, sincronizações, células, trechos e fragmentos rítmicos fortemente, nitidamente desenhados e escritos, pontuando, mas também ressaltando e acelerando a propulsão da peça. A sincronização de eventos, cujo peso maior não é o rítmico, contribui de maneira singular para a realização de outros acontecimentos que mais ainda delineiam a precisão. (Csekö 1996)

O tempo musical pensado por Csekö, apesar do rigor das sincronizações, expande-se através do uso sistemático da aleatoriedade, da liberdade de realização que é oferecida aos intérpretes, das repetições, da imprecisão dos módulos (retângulos modulares de simile), da improvisação, do uso sistemático do espaço gráfico proporcional ao som e do uso de registros de altura em vez de notas definidas. Suas obras, em geral, têm curta duração, e o jogo de dinâmicas, de grande variedade, é um fator de extrema importância para o desenvolvimento do seu discurso musical. As nuanças de dinâmica propiciam, juntamente com a duração e o ritmo, uma projeção da velocidade no acontecimento musical. No que diz respeito às alturas, Csekö trabalha com os registros agudo, médio e grave quase sempre grafados em trigramas e bigramas, dando aos intérpretes a opção de escolha das notas - o que, naturalmente, faz com que a mesma peça soe de forma diferente a cada execução. Quando a precisão de alturas e durações se faz necessária, o compositor lança mão da notação tradicional. Para ele "uma maior determinação das durações e das alturas é alcançada pela hibridização da notação gráfica com a notação tradicional. Daí essa modalidade ser chamada de Notação Gráfica Híbrida." (Csekö 2017, 255)

A liberdade para a improvisação nas obras de Luiz Carlos Csekö resulta em diversas possibilidades de manipulação com o som. Distorções, em contraponto à sonoridade convencional, também são exploradas, e contribuem para a textura tímbrica de suas obras. Quanto à harmonia, Csekö trabalha com clusters e acordes de grande densidade, além de usar constantemente batimentos e outros fenômenos acústicos que resultam do emprego de intervalos harmônicos muito próximos.

\section{Intérprete e Performance}

Em praticamente todas as suas obras, Luiz Carlos Csekö fornece aos intérpretes instruções detalhadas para uma performance adequada. Tais orientações, indicadas na bula e/ou na partitura, não abrangem apenas questões musicais (como as já mencionadas improvisação e aleatoriedade, por exemplo), mas sugerem como será a movimentação dos intérpretes em cena, os gestos a serem ressaltados, as intervenções no espaço cênico e o vestuário a ser utilizado - elementos fundamentais para a execução ao vivo de suas obras -, e são idealizadas ao mesmo tempo em que a composição musical é concebida, durante o seu processo de criação. Gestos e ações que podem passar despercebidos pelo público são, para o compositor, partes pujantes e indispensáveis à performance, e tais intervenções visuais podem desvendar, assim, os muitos detalhes do seu ideário musical, assumindo proporções maiores em sua obra. 
Os projetos de luz, concebidos e elaborados pelo próprio compositor, afloram da mesma maneira, simultaneamente à criação musical. Como parte complementar da execução, a escuridão natural dos teatros, durante os concertos, é interrompida através da ação planejada dos fachos de luz que riscam o espaço cênico alterando-o de forma peculiar. Esses fachos de luz, ao serem envolvidos pela fumaça de palco, assumem volume, contornos, superfícies e granulações, e os intérpretes - atores da performance sônica e cênica - contribuem, também, como objetos visuais de grande poder e intervenção, pontuando vigorosamente o conjunto da obra.

\section{Algumas obras vocais}

As primeiras obras do compositor Luiz Carlos Csekö escritas para voz datam do início da década de 1970. As múltiplas facetas do seu trabalho contribuíram para a formação e consolidação de um repertório substancial em que, quando da escolha desse instrumento, o amplo espectro sonoro de timbres e efeitos extramusicais (como na voz falada, sussurrada, murmurada, gritada, entre outras) servirá de referência para futuras obras vocais. Antes da análise de Sound, objeto de pesquisa do presente artigo, abordaremos algumas feições estéticas, estilísticas e técnicas de outras peças que julgamos ser importantes para uma melhor compreensão do pensamento musical do compositor ao trabalhar com a voz a cappella ou como parte integrante de um ensemble, solista ou em coro, microfonada ou não. Três obras, de diferentes períodos, foram selecionadas para tal. São elas: Der Epilog (1973), Divisor de Águas (1982a) e Noite do Catete 2 (2005).

\subsection{Der Epilog}

Durante o tempo em que estudou na Universidade de Brasília, Csekö compôs a sofisticada Der Epilog, que, com cerca de 7'40" de duração, segundo o compositor, pode ser executada respeitando qualquer uma das três formações propostas; a saber, seis vozes solistas amplificadas, seis duos, trios, quartetos e quintetos de solistas, também amplificados, ou coro misto, sem amplificação. A divisão a seis vozes compreende três vozes femininas (sem especificação quanto à tessitura vocal de soprano, mezzo ou contralto) e três vozes masculinas (igualmente sem especificar se tenor, barítono ou baixo). O texto é do escritor, poeta e dramaturgo alemão Günter Grass e, para a performance ao vivo, deve ser memorizado pelos intérpretes. Csekö recomenda, também, que todas as consoantes presentes no final de uma sílaba ou palavra devem ser exageradamente articuladas e pronunciadas com uma dinâmica o mais forte possível, mesmo que isso distorça o som. Em Der Epilog, Csekö utiliza, para as alturas, durante toda a partitura, o trigrama, e trabalha sistematicamente com diversas possibilidades de variação da voz falada, que, de forma "rápida", "lenta", "mais ou menos rápida" e "mais ou menos lenta" são indicadas como "dramaticamente", "monotonamente", "afirmando", "com desespero", "com ansiedade", entre outros, além dos sussurros e, em alguns poucos momentos, do Sprechgesang. Com diversos tipos de articulação, vibrati rápidos, médios e lentos, passagens rápidas, glissandi ascendentes e descendentes, mudanças súbitas e bruscas de dinâmicas, repetições via simile e alternâncias entre fórmulas de compasso e tempo cronometrado, a peça é rica em timbres, efeitos sonoros e de execução bastante complexa. Der Epilog estreou nos Estados Unidos em 1979, com o sexteto de solistas do Minnesota Composer's Forum Choir e regência. 


\subsection{Divisor de Águas}

A peça Divisor de Águas é dedicada ao barítono paraguaio, radicado no Brasil, Eládio Pérez-González, que, ao lado da pianista Berenice Menegali, estreou-a no Rio de Janeiro em 1983. Com cerca de 4'30" de duração, foi escrita para piano e barítono-recitante e tem como texto o poema homônimo do pintor e poeta baiano Antônio Brasileiro. O prefácio da partitura traz informações a respeito da performance ao vivo (com fachos de luz que envolvem o cantor, acompanhando sua movimentação pelo palco e pequenas luminárias instaladas no piano; facilitando, assim, a leitura do instrumentista; mas espalhando o mínimo de luz possível). O vestuário também está previsto, e Csekö propõem três possibilidades, ou combinações. $O$ texto, no entanto, é o elemento mais importante da peça. A pequena bula, com signos claros e de compreensão imediata, fornece aos intérpretes dados a respeito da execução. No que diz respeito às alturas, Csekö trabalha com trigramas, tanto para a voz quanto para o piano; porém, para este último, algumas vezes opta pelo pentagrama, com notas específicas grafadas na clave de sol. Os acordes realizados pelo piano são construídos através de intervalos de segundas maiores e menores criando clusters em diversas regiões do instrumento, e o uso de duas lâminas de metal ou plástico (como uma simples régua de plástico e uma barra de metalofone) se faz necessário para que o instrumentista possa esfregar as cordas por dentro do piano de forma contínua, além da recorrente percussão e dos glissandi que são realizados nas cordas em sentido paralelo ao teclado. Quanto à parte vocal, além da voz cantada, com alturas aproximadas, Csekö trabalha com a voz falada e com o Flatterzunge ${ }^{2}$. Os jogos de alternância entre intervalos distantes (exigindo do intérprete-cantor, em alguns momentos, o uso do falsetto com vibrato exagerado) e a conexão melódica via glissandi são características do contexto melódico da peça. No entanto, durante todo o discurso musical de Divisor de Águas, nota-se a predominância da voz falada-recitada, enfatizando o texto de Antônio Brasileiro. Aqui, a relação entre música e cena é estreitada, exigindo do cantor uma atuação mais do que simplesmente musical. A realização cênica da obra e o desafio de extrair da partitura a música complexa ali notada é lançado ao intérprete, desobstruindo-o, assim, da tradicional abordagem instrumental, notacional ou estilística.

\subsection{Noite do Catete 2}

Importante peça composta para vozes a cappella, Noite do Catete 2 tem cerca de 3'55" e é parte integrante da série de mesmo nome 3 idealizada por Luiz Carlos Csekö. Como em Der Epilog, em Noite do Catete 2, Csekö propõe duas possibilidades de execução, indicando as seguintes formações: quatro vozes femininas (sendo três vozes pré-gravadas e uma voz ao vivo, amplificada), e qualquer combinação de vozes femininas ao vivo e pré-gravadas. O texto é composto por excertos do poema Definição de amor, do poeta baiano Gregório de Matos, e o compositor, em nota registrada em suas observações, prefaciada à partitura, requer que o poema em questão seja impresso em panfleto e distribuído junto com o programa do concerto. Fragmentos da música Juazeiro, de Humberto Teixeira e Luiz Gonzaga, também são utilizados, mas apenas a melodia, sem o texto, deverá ser cantada. Aqui, Csekö expõe de forma detalhada e precisa as diretrizes para que a peça aconteça. Orientações sobre o vestuário (vestido de cor branca ou preta, com amplo decote nas costas, semijusto e sapatos de salto alto) e a descrição dos equipamentos de luz e som que deverão ser utilizados durante a performance, tal como o projeto de iluminação e as duas possibilidades para o projeto cênico

\footnotetext{
${ }^{2}$ Frulatto em alemão.

${ }^{3}$ No total nove peças integram a série denominada Noite do Catete.
} 
(light design e scenic design), riquíssimos em detalhes, com os mapas de cena e luz em anexo, além do projeto sônico (sonic design) somam-se às informações inerentes à realização musical, contidas na bula da peça, e fazem referência aos símbolos criados para a execução da obra. Em Noite do Catete 2, novamente, Csekö trabalha com trigramas, voz falada, murmurada e sussurrada. O improviso também se faz presente, e os fragmentos da música Juazeiro, escolhidos livremente pela(s) intérprete(s), devem ser executados sempre em bocca chiusa nos registros grave e médio-grave. A peça é rica em contrastes e dinâmicas, e a polifonia vocal resulta no que o compositor chama de "contraponto de dinâmicas; um complexo jogo de nuances e contrastes, onde vários planos acústico-espaciais são criados, contribuindo com intervenções no espaço de realização do evento." (Csekö 2003)

\section{Sound (1982)}

Foi no início da década de 1970, durante sua temporada na Columbia-Princeton Electronic Music Studio, em Nova York, quando estudou e trabalhou com Vladimir Ussachevsky, que Luiz Carlos Csekö teve o seu primeiro contato com a música eletrônica, bancos de sintetizadores e geradores de som, mas a técnica de cortar fitas com lâminas especiais e uni-las através de fitas adesivas, apesar de estimulante, não o impulsionava a compor. Quando retornou dos Estados Unidos, no início da década de 1980, Csekö percebeu que não havia muitos estúdios especializados - ou em processo de desenvolvimento - em música eletroacústica no país; é quando conhece os compositores Rodolfo Caesar e Aquiles Pantaleão, no Estúdio da Glória ${ }^{4}$, e passa a observar as primeiras experiências com música eletrônica realizadas no Rio de Janeiro.

A busca por novos timbres sempre foi uma constante no trabalho de Luiz Carlos Csekö, e, mesmo antes de trabalhar com sons gravados e manipulados em estúdio, o compositor se propunha a conjugar a tímbrica tradicional às novas sonoridades que descobria ao reinventar a maneira de se tocar instrumentos acústicos. As diversas sonoridades - resultado de tais experiências - aguçavam ainda mais a sua imaginação e foi durante o convívio com a música eletroacústica no Brasil, e com os compositores que frequentavam o Estúdio da Glória, que Csekö se propôs, pela primeira vez, a trabalhar em música erudita com microfones e amplificação numa área de baixa tecnologia, dentro de um espectro de som que gerava resultados sonoros muito próximos dos sons que eram produzidos e manipulados nos estúdios de gravação. A partir de então, decidiu compor utilizando microfonação e amplificação, e, assim, passou a desenvolver, em suas obras, o que costuma chamar "amálgama eletroacústico". Ele define o termo como

um empilhamento de partes microfonadas, cujo material é composto para ser microfonado; ele não é um material acústico. Ele vai somente ser realizado completamente, quando for microfonado, pela metalicidade, pela própria expansão tímbrica, harmônica, dinâmica, que a microfonação e amplificação dão. Esse material, ao ser acoplado, nas partes pré-gravadas, vai produzir um quarto, quinto, sexto resultado, porque são pensadas assim, são compostas assim. Ou seja, elas são compostas já para serem o que elas são e não para, através da microfonação, aí talvez...não, não, eu tenho

\footnotetext{
${ }^{4}$ Considerado um dos maiores núcleos de produção eletroacústica do Brasil, o Estúdio da Glória foi fundado em 1981 por Rodolfo Caesar e Tim Rescala. Também colaboraram com o seu desenvolvimento compositores como Aquiles Pantaleão, Sandra Lobato, Tato Taborda, Rodrigo Cicchelli e Vânia Dantas Leite. (Garcia 2012, 105-106)
} 
um som que vai ser realizado por isso. Chamo de amálgama eletroacústico por falta de qualquer outro nome. Não quero entrar de gaiato em uma área em que, em absoluto, tenho qualquer possibilidade de trabalhar, porque não tenho conhecimento dela, e é muito complexa, e eu tenho um grande respeito. (Csekö apud Puig 2014)

"A sound of silence on the startled ear"5. É na pequena frase de um dos poemas mais longos escritos no início do século XIX - Al Aaraaf, do poeta norte-americano Edgar Allan Poe - que Luiz Carlos Csekö se inspirou para compor Sound, em 1982, para quatro vozes femininas, luz, cena e amplificação. O poema de Poe, com o excerto destacado utilizado por Csekö como epígrafe da peça, é baseado em histórias do Corão e se passa num âmbito entre o Céu e o Inferno, uma vida após a morte, numa espécie de purgatório, onde os que lá estão não sofrem qualquer tipo de punição, mas ainda não alcançaram a paz e o gozo esperados em uma vida no paraíso celestial (Poe 2008). Sound é dedicada ao compositor norte-americano Tim Lenk, que Csekö conheceu durante sua temporada na University of Colorado, e só foi estreada dez anos após a sua criação, em 1992, no Rio de Janeiro, na qual Lucila Tragtenberg, ao interpretar ao vivo uma das vozes, dialoga com as outras três, gravadas previamente por ela em estúdio.

Em suas observações, que antecedem o texto musical, Csekö orienta a intérprete a, durante a performance, pronunciar todas as sílabas, vogais e consoantes presentes na palavra sound, em inglês britânico ou norteamericano. As quatro vozes deverão ser vozes solistas e estar amplificadas. Desse modo, qualquer combinação de vozes femininas amplificadas e/ou gravadas poderá ser utilizada. $O$ espaço de realização da obra interfere decisivamente na formação da tímbrica da peça, e o projeto cênico leva em consideração a disposição do grupo de solistas no palco, possibilitando o melhor resultado acústico-espacial-cênico possível. De acordo com Csekö (1982b), as intérpretes deverão criar um gestual sutil e sensual para a execução da peça, e sua linguagem corporal deverá remeter ao prazer de produzir cada evento sonoro, moldando plasticamente o corpo do som. Para tal, o compositor, em seu projeto de iluminação, sugere emoldurar as intérpretes através de focos de luz ovais com bastante nitidez e de cor branco-leitosa, intensa e brilhante como numa moldura ou espelho antigo. Csekö, também, recomenda que, no caso de uma cantora interpretar a peça de forma eletroacústica-mista, ou seja, simultaneamente às gravações realizadas previamente, deverão ser utilizados quatro hologramas da cantora solista em tamanho natural, projetados tridimensionalmente em vários locais do palco e auditório durante a performance ao vivo. Cabe, aqui, o comentário do compositor, em sua tese de doutorado, de que "Sound está entre as primeiras obras de música erudita experimental a realizar uma interação com a holografia." (Csekö 2017, 137)

A respeito das interfaces entre canto e performance, Lucila Tragtenberg (1997) lembra que, na interpretação da música vocal, o papel da cena sempre esteve associado à ópera e que, na música de câmara tradicional, movimentos e gestos moderados, sóbrios, por anos mantiveram o intérprete-cantor demasiadamente estático e, muitas vezes, inexpressivo. Percebe-se, no entanto, que, desde o início do século XX, na música de câmara, "inicia-se um processo em que a dimensão da música (enquanto discurso sonoro que se desenvolve no tempo) é ampliada para um espaço cênico." (Tragtenberg 1997, 28) Dessa forma, a música de câmara moderna e contemporânea ganha em espacialidade, onde o aspecto visual é, a todo momento, enfatizado. Na música de Luiz Carlos Csekö, o trabalho cênico cria uma atmosfera dramática e, como destaca Tragtenberg, suas indicações são ricas nesse sentido. O compositor indica, na partitura, muitos elementos

5 "Um som de silêncio que aturdia o ouvido." Tradução nossa. 
cênicos ao intérprete, como seu figurino, movimentação, intenções expressivas que deseja para trechos cantados ou falados, a iluminação da peça. Seu universo é conjunto, cênico e musical. (ibidem, 34)

Em Sound, com cerca de 3'20" de duração, Csekö trabalha com o tempo cronometrado em blocos de circa $5^{\prime \prime}$, além de trigramas, e unagramas, voz sussurrada, voz falada e ligeiramente cantada. Como mostra a Figura 1 a seguir, assobios, respirações ruidosas e lentas expirações também fazem parte das técnicas expandidas exploradas por Csekö.

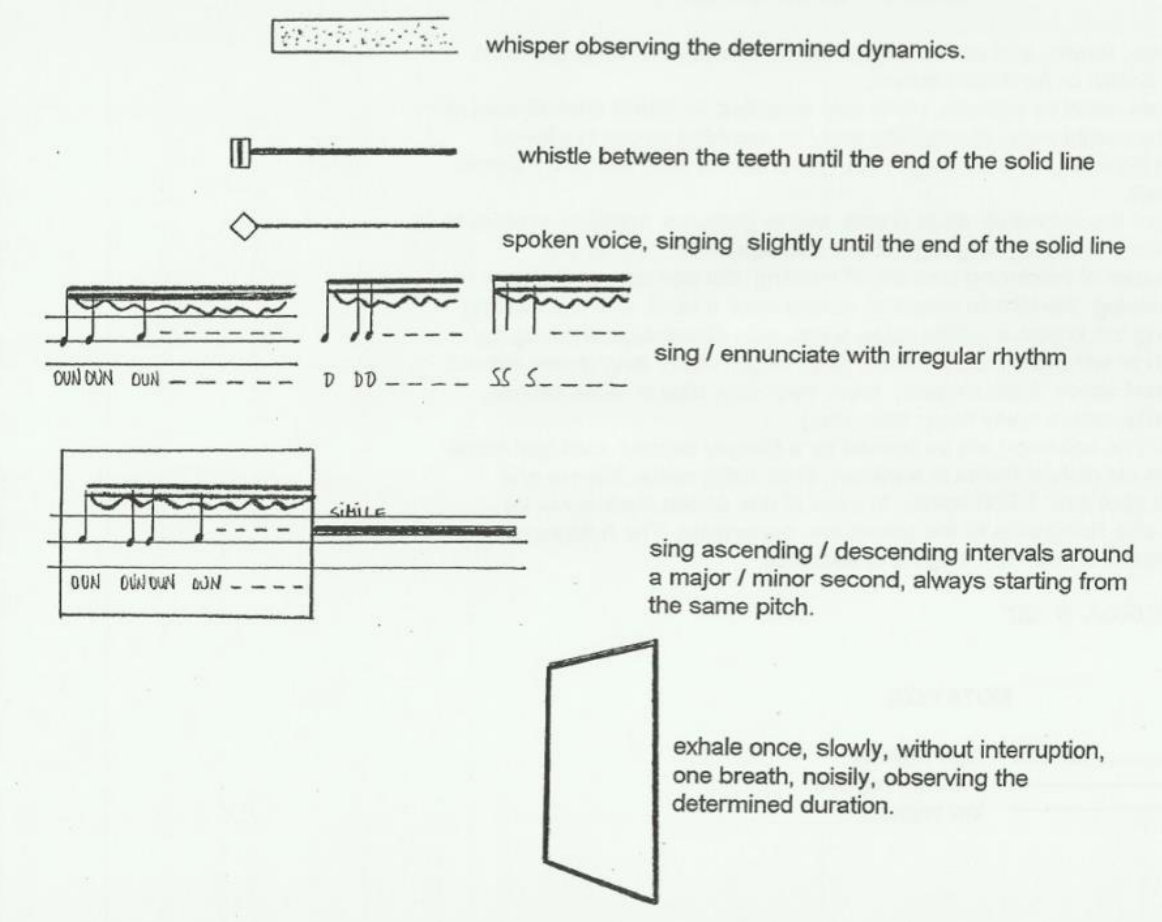

Figura 1: L. C. Csekö: Sound, bula p.2. Cópia manuscrita do compositor, 1982

O texto da peça é desenvolvido a partir da desconstrução da palavra de origem inglesa "sound", e todo o material sonoro inerente, além do som natural das letras $S, O, U, N, D$, dinâmicas de articulação, sibilos, silvos, estalidos e demais ruídos que resultam da voz falada e cantada - que, para serem ouvidos, precisam ser cuidadosamente amplificados via microfonação - , é utilizado como material sonoro composicional. Através de repetições sistemáticas e do rearranjo das letras que formam a palavra sound, gerando espécies de anagramas, o compositor desenvolve o seu texto. Algumas possibilidades fonéticas são "OUN", "D" e "NN", entre outras.

Em obras anteriores, Csekö já havia trabalhado com os efeitos vocais que afloram da emissão das palavras contidas nos poemas, mas foi em Sound, no qual o texto integral se resume a uma palavra, apenas, que o compositor decide priorizar a sonoridade contida ali a seu significado. Sound, portanto, é um excelente exemplo de como traduzir o texto (neste caso, a palavra) em textura, extraindo dele as múltiplas possibilidades dramáticas e um amplo espectro de cores e sons. 


\subsection{Melodia e Harmonia}

Como em quase todas as suas obras, Sound não tem uma melodia fixa, regular. O uso sistemático da improvisação e da aleatoriedade, abrangendo todos os aspectos da peça, contribuem para a sua realização, e através desses procedimentos o compositor convida a intérprete a participar do momento composicional, contribuindo para a variedade e transitoriedade da obra. As melodias - e blocos harmônicos - geradas em Sound vêm à tona quando a intérprete é orientada a cantar intervalos ascendentes e descendentes de segunda maior e menor, começando sempre com a mesma nota. Para tal, o compositor usa, de forma alternada, a letra "N" em uma das vozes e a sílaba "OUN" nas outras três (como podemos observar na Figura 2):

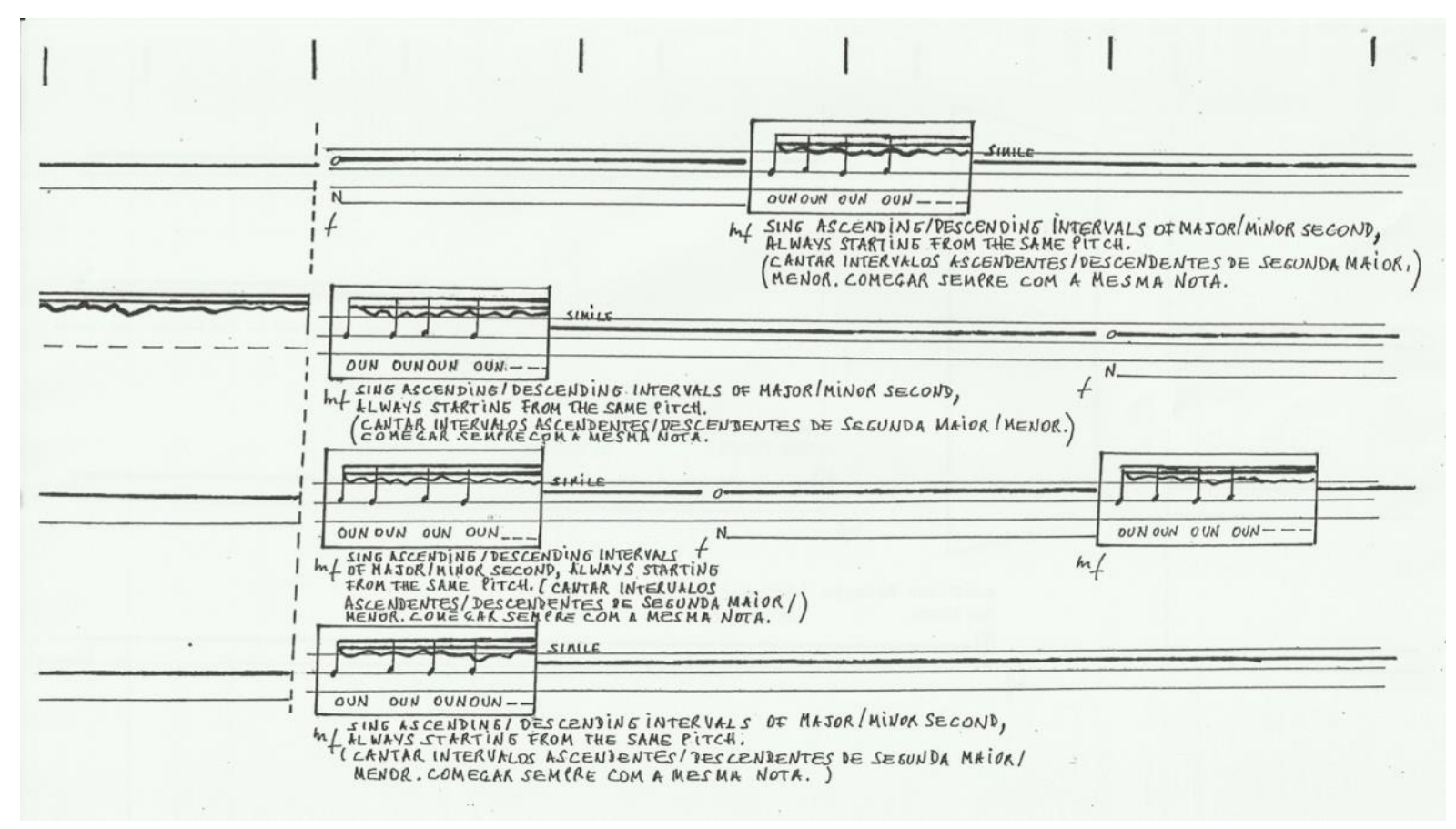

Figura 2. L. C. Csekö: Sound, p. 4. Cópia manuscrita do compositor, 1982

Os acordes (aqui, clusters) são estabelecidos a partir dos contrapontos ondulantes e efêmeros, intensamente contrapostos ao perfil anguloso de um jogo de alturas formados por saltos e longos contornos melódicos e podem variar sempre que a peça for executada.

\subsection{Ritmo}

Csekö (1996) diz que seu tempo musical é vertiginosamente compactado pela duração curta de suas obras e pela precisão dos fragmentos e células rítmicas o que resulta em um contraponto rigoroso e fluido. Diferente do que acontece na maioria de suas peças, em Sound, o ritmo, realizado pelas quatro vozes, é bastante simples, e, numa primeira análise da partitura, nota-se estar presente, apenas, nas repetições irregulares das letras " $S$ " e " $D$ ". Entretanto, nessa obra, a rítmica determinante não se caracteriza pelas curtas células horizontais que conferem unidade à peça; mas, num contexto mais amplo, pelos blocos de eventos sonoros que são entrecortados pelo silêncio. Tais blocos, verticais, são organizados e separados por momentos de silêncio (pequenas pausas) que têm o mesmo valor e importância do som. Em Sound, gestos que produzem o som produzem também o silêncio, e conferem à obra uma maior intensidade rítmica. 


\subsection{Descrição da obra}

Para quatro vozes femininas, a peça começa com uma expiração/respiração ruidosa realizada pelas vozes 1, 2 e 3, enquanto a voz 4 emite de forma ininterrupta, logo em seguida, numa dinâmica que vai do $p p$ ao $m f$, a letra "S". Cerca de cinco segundos depois as primeiras três vozes unem-se à quarta em "S", de $p$ a $m f$. Após um breve momento de silêncio, as quatro vozes retornam em " $\mathrm{S}$ ", mas agora de $f f$ a $f f f$, e o volume de som aumenta de forma progressiva culminando no ataque da letra " $D$ ", que é seguido, mais uma vez, por silêncio. Os dois blocos sonoros que dão início à peça se repetem, mas numa dinâmica mais forte (Figura 3).

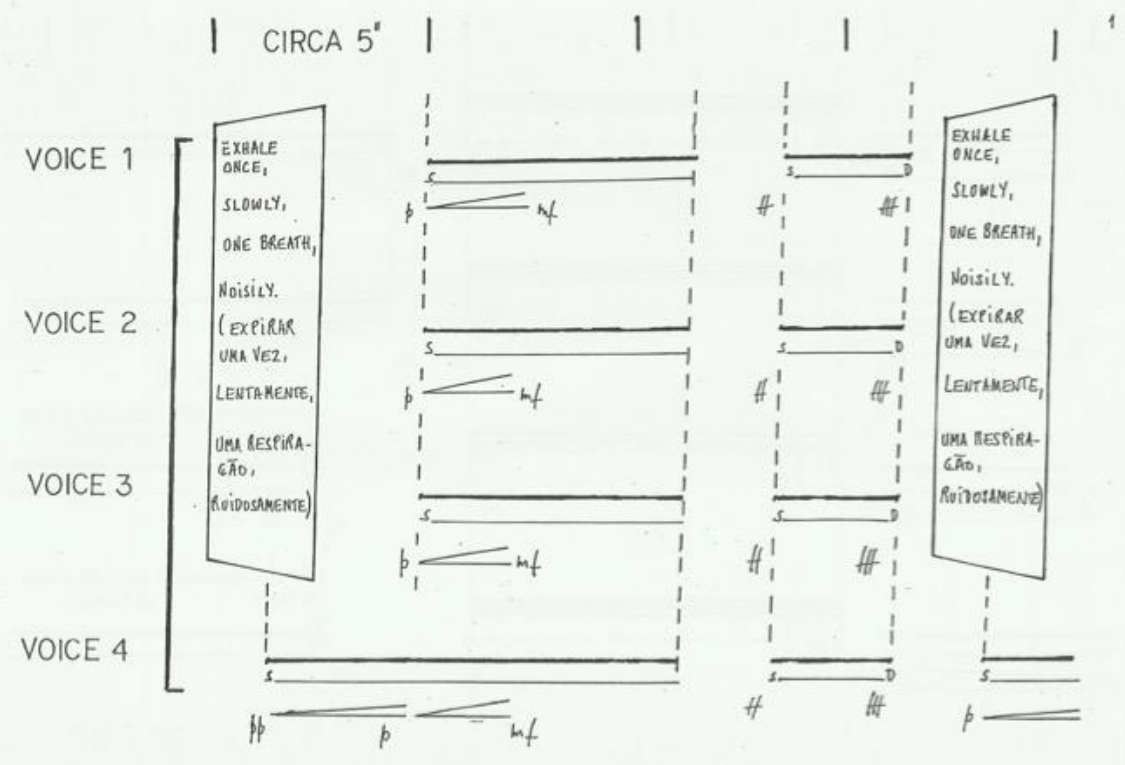

Figura 3: L. C. Csekö: Sound, p. 1. Cópia manuscrita do compositor, 1982

Após um novo breve momento de silêncio, as quatro vozes, de forma irregular, articulam ritmos diferentes em " $\mathrm{S}$ " durante cerca de oito segundos até um novo ataque da letra " $D$ ". Silêncio. As vozes 1 e 2 emitem, em $m f$, a letra " $S$ " que segue de forma ininterrupta enquanto, logo em seguida, as vozes 3 e 4 , também em "S", assobiam, criando novo timbre, um novo espectro sonoro (Figura 4).
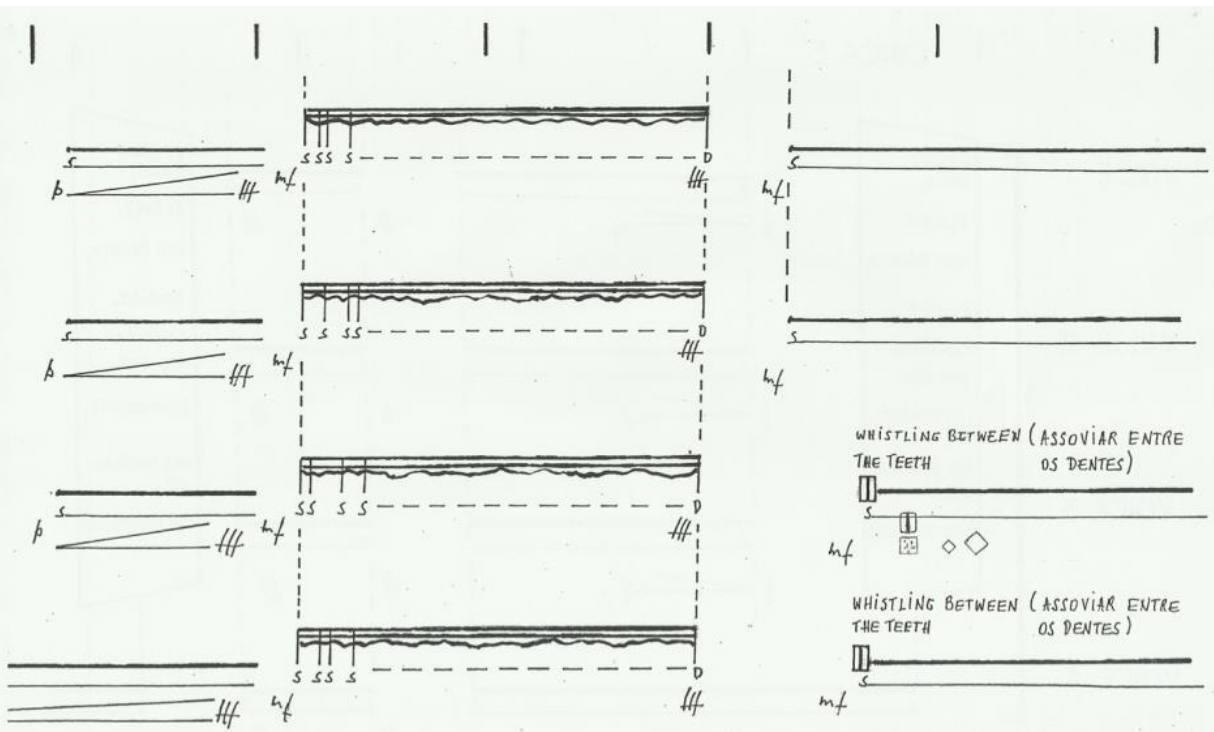

Figura 4: L. C. Csekö: Sound, p. 2. Cópia manuscrita do compositor, 1982 
Após cerca de quinze segundos, e do silêncio que entrecorta toda a peça, o compositor remete o ouvinte, mais uma vez, ao início de Sound; mas, agora, enquanto as vozes 1, 2 e 3 expiram/respiram, a voz 4 emite de forma ininterrupta a letra " $\mathrm{S}$ " assobiando. Cerca de cinco segundos depois, as primeiras três vozes unemse à quarta em " $\mathrm{S}$ ", mas dessa vez as vozes 1 e 2 mantêm o " $\mathrm{S}$ " de forma ordinária enquanto as vozes 3 e 4 assobiam. Subitamente, a voz 2 passa a articular o " $\mathrm{S}$ " de forma ritmicamente irregular por cerca de doze segundos e, após um breve momento de silêncio, melodia e harmonia vêm à tona quando as vozes 2 , 3 e 4 passam a cantar, em "OUN", com ritmos irregulares e numa dinâmica $m f$, intervalos ascendentes e descendentes de segunda maior e menor, enquanto a voz 1 mantém, em $f$, apenas uma nota, em registro médio-agudo, usando a letra "N" (Observe a Figura 2).

Esse bloco se desenvolve através da espacialização da nota realizada em registro médio-agudo, usando a letra "N", que passará da voz 1 para as vozes 3, 2 e 4, durante cerca de trinta segundos, nessa ordem, culminando no súbito ataque da letra " $\mathrm{D}$ " em ff. Silêncio. Expiração/respiração ruidosa, mais uma vez. As quatro vozes emitem ao mesmo tempo e no mesmo registro médio-agudo a letra " $\mathrm{N}$ ", seguindo do $p$ ao $\mathrm{mf}$ até mais um breve silêncio. $O$ bloco é repetido; porém a dinâmica, agora, segue num crescente em direção ao $f$, até o surgimento de um novo evento, no qual as quatro vozes, de forma irregular, articulam em $f f$ ritmos diferentes em " $\mathrm{D}$ " durante cerca de cinco segundos, quando atingem, em " $\mathrm{N}$ " no registro médio, um momento de emissão linear, que, agora, tem o seu fluxo de som interrompido através de acentuações irregulares em $\mathrm{fmp}$. Os curtos ataques em " $\mathrm{N}$ ", nas quatro vozes, passam aos ritmos irregulares em " $\mathrm{D}$ ", com dinâmica em $f f$, e permanecem por pouco tempo, até o retorno do assobio em " $\mathrm{S}$ ". As vozes 1 e 2 mantêm o assobio enquanto, cerca de cinco segundos depois, as vozes 3 e 4 intervêm, mais uma vez, com os ritmos irregulares em "D" (Figura 5).

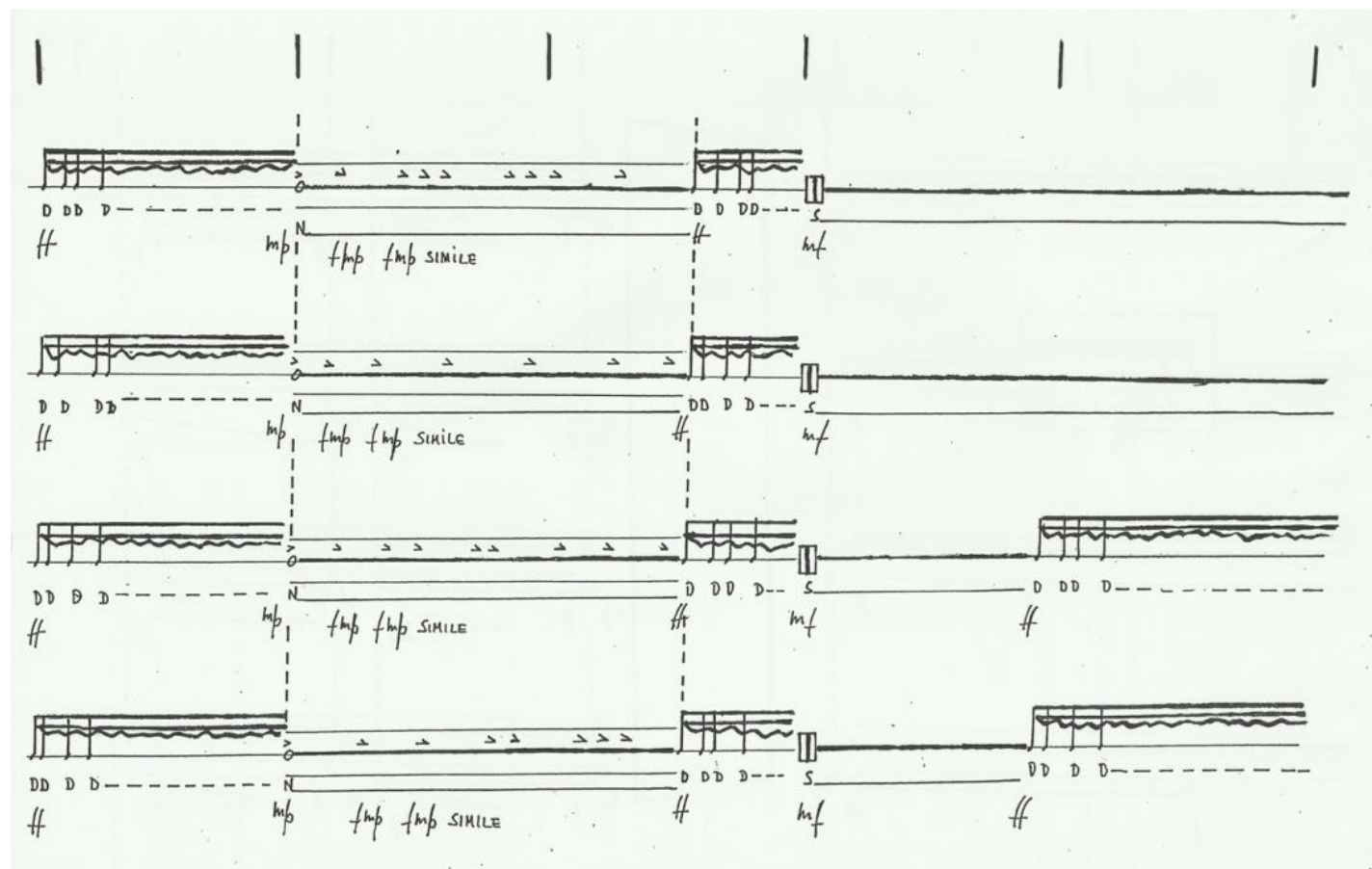

Figura 5: L. C. Csekö: Sound, p. 6. Cópia manuscrita do compositor, 1982

Expiração/respiração ruidosa, súbita. Silêncio. A palavra sound é emitida mais uma vez durante o trecho de maior movimento e variedade sucessiva num curto espaço de tempo quando as quatro vozes articulam "S", "OUN" em registro médio-agudo, criando uma harmonia aleatória, e "D" com ritmos irregulares. 
Subitamente, as vozes 1 e 2, de forma ordinária, emitem de forma ininterrupta o som da letra " $\mathrm{S}$ ", e as vozes 3 e 4 passam a assobiá-la. Cerca de cinco segundos depois, o compositor constrói, através dos ritmos irregulares presentes nas articulações da letra " $D$ " (vozes 1 e 3) e da combinação aleatória de melodias criadas a partir da emissão em "OUN" dos intervalos ascendentes e descendentes de segunda maior e menor (vozes 2 e 4), uma nova harmonia (Figura 6) e, de forma súbita, pela primeira vez a palavra sound é sussurrada.

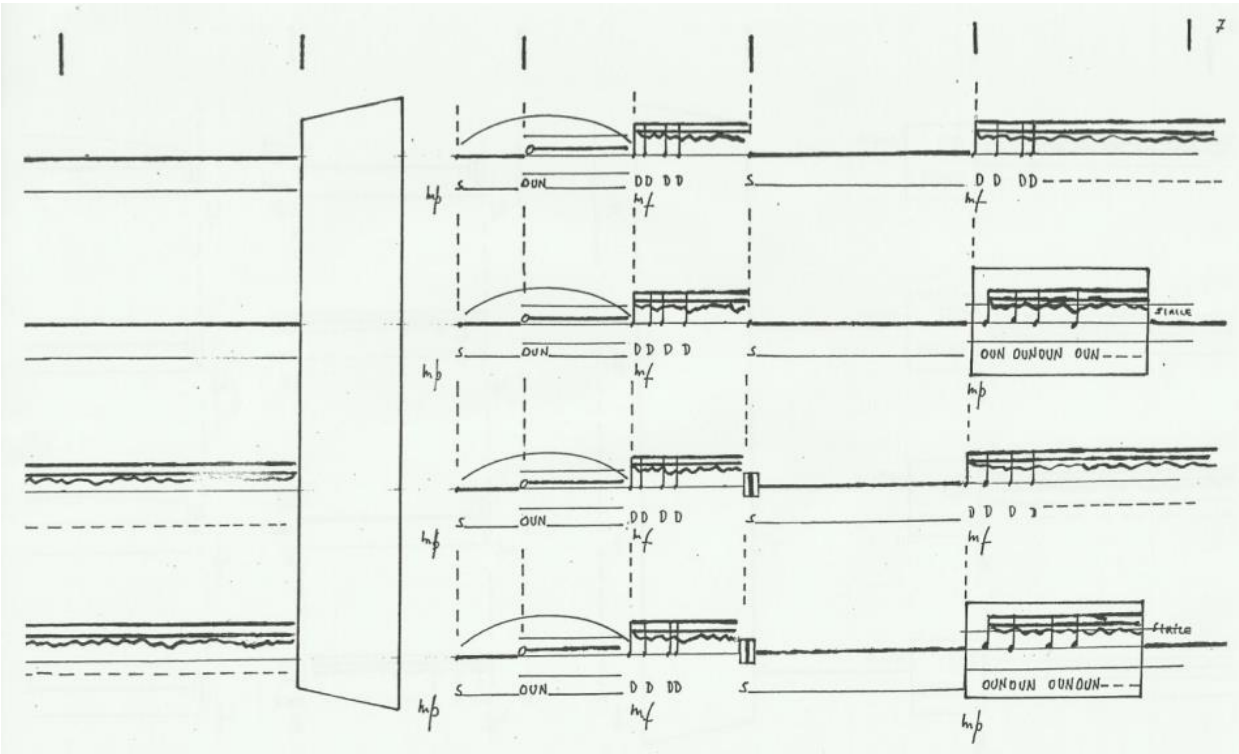

Figura 6: L. C. Csekö: Sound, p. 7. Cópia manuscrita do compositor, 1982

Sound é sussurrado pelas quatro vozes diversas vezes numa dinâmica $f f$ e segue até uma nova expiração/respiração ruidosa. Silêncio. " $\mathrm{D}$ " $f f$. Mais uma vez, silêncio. " $\mathrm{D}$ ”. Em $m f$, as vozes 1 e 3 assobiam enquanto as vozes 2 e 4 articulam ritmos irregulares em " $\mathrm{S}$ " até que as quatro vozes se encontram num sussurro em "OUN". Silêncio. A palavra sound é emitida novamente; todavia de forma alargada, quando os assobios em "S", agora nas quatro vozes, convertem-se na sílaba "OUN" de forma falada, ligeiramente cantada e terminam no seco ataque da letra " $D$ ". Silêncio. Num tempo ad libtum a palavra sound é emitida uma última vez quando as quatro vozes sussurram de forma alargada "S" - "OUN" - "D" (Figura 7).
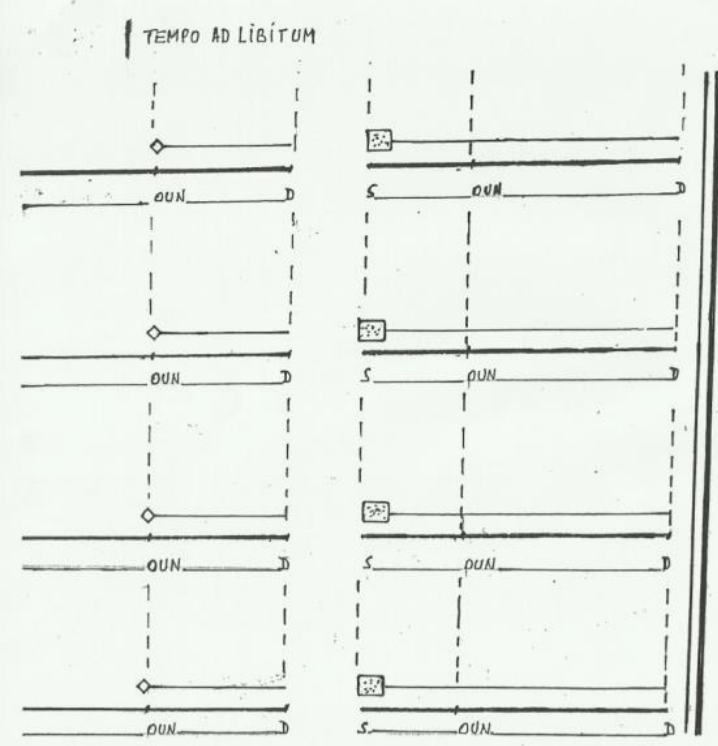

Figura 7: L. C. Csekö: Sound, p. 9. Cópia manuscrita do compositor, 1982 


\section{Considerações}

Quando se refere às suas obras vocais, o compositor Luiz Carlos Csekö afirma que o texto utilizado por ele, as palavras, sílabas ou mesmo fragmentos dispersos, apenas, relacionam-se muito mais com o som do que com o seu significado, ou seja, os diversos modos de fonação - sussurrado, soproso, fluido (música de concerto), neutro (música popular) e tenso (voz gritada) - , ligados às variações de dinâmica ( $p p, p, m p, m f$, $f, f f$ etc) e atuando diretamente sobre o timbre vocal, passam a ser, para o compositor, matéria prima para a elaboração dessas obras. Sendo assim, o uso sistemático de tais elementos, o som que resulta da microfonação e amplificação, além da disposição dos intérpretes em cena, tal como o local de realização das suas obras vocais, são tomados como elementos fundamentais para a formação timbrística e concepção de tais obras.

A audição e análise das obras vocais apresentadas no presente artigo - em especial, Sound - estimularam nossa pesquisa no campo da escrita para voz e das possibilidades sonoras para esse instrumento na música de concerto contemporânea. Em Sound, a utilização da voz, de maneira expandida, resulta em sonoridades, efeitos e timbres particulares, e, apesar de muitos compositores e obras vocais concebidas a partir da segunda metade do século XX até os dias de hoje não terem sido contemplados aqui, não negamos, de forma alguma, sua importância. Sound, uma peça de curta duração, construída a partir de poucos elementos, mas que possuem um grande peso de identidade, é um exemplo significativo da produção vocal de Luiz Carlos Csekö, onde este compositor trabalha com diversas técnicas expandidas num amálgama eletroacústico, ampliando a gama de possibilidades a cada experiência e a cada nova interpretação da mesma obra, utilizando apenas cinco letras.

\section{Referências}

Csekö, Luiz Carlos. 1973. Der Epilogue. Partitura. Cópia manuscrita do compositor. Brasília. (23 páginas). Para seis vozes solistas amplificadas (ou coro misto sem amplificação).

Csekö, Luiz Carlos. 1982a. Divisor de Águas. Partitura. Cópia manuscrita do compositor. Rio de Janeiro. (5 páginas). Para voz e piano.

Csekö, Luiz Carlos. 1982b. Sound. Partitura. Cópia manuscrita do compositor. Rio de Janeiro. (9 páginas). Para quatro vozes femininas.

Csekö, Luiz Carlos. 1996. Domains of Fugacity. Excertos da conferência proferida na Juilliard School of Music e Columbia University. New York/EUA. Manuscrito do autor.

Csekö, Luiz Carlos. 2003. Trajetória em Corda Bamba. Excertos da conferência proferida na Academia Brasileira de Música. Rio de Janeiro/Brasil. Manuscrito do autor.

Csekö, Luiz Carlos. 2005. Noite do Catete 2. Partitura. Cópia manuscrita do compositor. Rio de Janeiro. (12 páginas). Para quatro vozes femininas.

Csekö, Luiz Carlos. 2017. Domínios da Fugacidade: A abordagem composicional de LC Csekö. Tese (Doutorado) - Universidade Federal do Estado do Rio de Janeiro (Unirio). 
Garcia, Denise. 2012. Estúdio da Glória, década de 80: Polo de produção Eletroacústica no Brasil. In: IV Seminário Música Ciência Tecnologia: Fronteiras e Rupturas. n. 4. http://www2.eca.usp.br/smct/ojs/index.php/smct/article/view/59 Acesso em 10/06/2021.

Poe, Harry Lee. 2008. Edgar Allan Poe: An Illustrated Companion to His Tell-Tale Stories. New York: Metro Books.

Puig, Daniel. 2014. Conversa com Luiz Carlos Csekö. In: LINDA - Revista semanal sobre cultura Eletroacústica. Rio de Janeiro. http://linda.nmelindo.com/2014/10/conversa-com-luis-carlos-cseko/ Acesso em $15 / 05 / 2021$.

Rebel, Diogo. 2015. Stimmung, Tehillim e Sound: reflexões a respeito da voz na música de concerto contemporânea. Dissertação - Mestrado. Universidade Federal do Estado do Rio de Janeiro (UNIRIO).

Tragtenberg, Lucila. 1997. Intérprete-Cantor: processo interpretativo e reciprocidade criativa com o compositor na música contemporânea através dos intérpretes da obra vocal de Luiz Carlos Csekö. Catálogo geral da sua obra vocal solo. Dissertação - Mestrado. Universidade Federal do Rio de Janeiro (UFRJ). 